\title{
Experimental and Computational Study on Concrete Filled PVC Plastic Tubes Placed In Columns \\ ${ }^{\text {"1}}$ Rajendra Khapre, ${ }^{2}$ Kamesh Gonnade \\ ${ }^{1,2}$ Shri Ramdeobaba College of Engineering and Management, Nagpur \\ Email: khaprern@rknec.edu, kameshgonnade21@gmail.com
}

Received: 06th November 2019, Accepted: 10th February 2020, Published: 29th February 2020

\begin{abstract}
Concrete filled PVC plastic tubes (CFPT) placed in column are formed by inserting concrete filled PVC plastic tubes inside the concrete column. This paper presents experimental and analytical analysis of CFPT. Plastics have low bonding with the concrete, so scratching was done on plastic tubes to increase the bonding. The inner diameter of tube used for making cubes was $100 \mathrm{~mm}$. Plastic tube was placed at the center of the cube. M20 grade of concrete was used for making of cubes and for filling plastic tubes. Specimens were cured for 28 days and tested under UTM machine for axial loading. All the data of specimen loading and load-displacement relationship were noted from UTM machine. In this study, a non-linear finite element model was also developed using ANSYS software to deal with characteristics of concrete and PVC tube. The validation of model was done by comparing computational results with experimental results. The validated FE model was used for parametric study like behavior of CFPT placed in column by changing diameter of tube, thickness of tube, number of tube and L/D ratio of CFPT placed in column. From the study, it is observed that there is decrease in hoop stress in $\mathrm{PVC}$ tube with increase in diameter of tube, thickness of tube and L/D ratio.
\end{abstract}

Keywords

ANSYS, Finite Element Method, CFPT, PVC Tube

\section{Introduction}

Columns are the vital members in structural system. Entire structure will be destabilized if there will be weakness or failure of column. Failure of column may lead to partial or total collapse of the structure. So, to prevent the failure and collapse it is necessary to improve the ductile deformation capacity of column. Nowadays composite columns are getting more importance in structural system due to their usage in seismic resistance. In this paper, plastic tubes are placed in columns which may increase the compressive strength, flexibility.

Experimental study on CFPT placed in columns was carried out by Gopi and Sujitha (2017).[2] It was reported from the experimental results that the $75 \mathrm{~mm}$ diameter tube increases the strength of concrete. Experimental study on Fiber Reinforced Polymer (FRP) tube reinforced concrete columns under different loading conditions was carried out by Wang et al. (2016). [10] It was observed from the experimental results that the axial load-carrying capacities of FTRC columns are higher than that of Group REF columns under both concentric and eccentric loadings. It was also reported that the axial load carrying capacity of FTRC columns is significantly reduced with the increase of eccentricity. There was an increase in ductility of FTRC columns with the increase of load eccentricity and higher bending moment capacity may be obtained for FTRC specimens. Gobinath and Selvi (2014) [1] had performed an experimental investigation for the effectiveness of PVC tube for confinement of concrete columns. It was reported that PVC may be used to achieve good axial compressive strength, penetration control and corrosion.

Idan (2017) [6] has proposed a nonlinear finite element model of Concrete-filled Aluminium tube columns using code ANSYS to study the confining effect over concrete core by the aluminium tube. It was reported that specimens with higher concrete strength experienced an increase in ultimate load capacity but decrease in ductility after failure. Gupta et al. (2006) [4] had done an experimental and computational study of concrete filled steel tubular columns under axial loads. From the experimental and computational study, it was found that for a specific deflection the load carrying capacity decreases with the increase in percentage volume of fly ash up to $20 \%$ for both modes of collapse of CFT columns but it again increases at $25 \%$ fly ash volume in concrete. Gupta (2013) [3] had done an experimental investigation for the effectiveness of UPVC tube for confinement of concrete columns. It was found that the variation between predicted capacities of columns using different models and the experimental capacities are within $\pm 6 \%$. So UPVC tubes can be effectively used for confinement of the concrete columns, improves their load bearing capacity, ductility as well as energy absorbing capacity. Article by Gupta and Verma (2014) [5] presents experimental study on 72 reinforced concrete filled unplasticized poly-vinyl chloride tubular column specimens having varying diameter subjected to contact with artificial sea water for the period of 6 months. Test results revealed that there is no degradation in strength or ductility of reinforce concrete columns when covered with unplasticized poly-vinyl chloride tube. 
Experimental study on concrete filled, unplasticized poly vinyl chloride (UPVC) tubes was carried out by Usha and Eramma (2014). [9] It was reported from the experimental results that with increase in length the strength was increased and it was higher for the concrete mix having $6.3 \mathrm{~mm}$ size of coarse aggregate compared to $10 \mathrm{~mm}$ size of coarse aggregate.

As Finite Element method has attained a stage maturity, numerical analysis can be carried out as a good alternative to experiments to examine the behavior of composite columns. A Finite Element model of cube specimen is developed using code ANSYS to study the non-linear behavior. In this paper, a non-linear 3D FE model of cube composed of axial compression. Experiments were also performed to validate the computational Finite Element model and the results of experiments are compared with the computational results. On the basis of the validation result, the validated computational FE model was used to study the behavior of concrete filled PVC plastic tubes placed in column by changing diameter of PVC tube, thickness of PVC tube, number of tubes and L/D ratio of column using ANSYS code.

\section{Experimental Investigation}

Experimental work was done to have identification of material properties which will be incorporated in ANSYS software.

\section{Identification of PVC Tube Properties}

Poly Vinyl Chloride (PVC) plastic tube of internal diameter $100 \mathrm{~mm}$ and thickness of $2 \mathrm{~mm}$ used in making cubes. To know the modulus of elasticity of PVC tube, hollow PVC tube specimen of height $150 \mathrm{~mm}$ was placed under UTM for compression testing. Axial load was applied on cross section till the tube cracks or load starts decreasing and load-displacement data was taken from UTM. The compressive strength of specimen was found out to be $37.69 \mathrm{MPa}$. Stress-strain curve was also plotted and the modulus of elasticity of PVC Tube was computed as, $\mathrm{Ep}=702.9 \mathrm{MPa}$.

\section{Identification of Concrete Properties}

Various materials like cement, fine aggregate, coarse aggregate and PVC tube were used in making of concrete. OPC of 43 grade confirming to IS:8112-1989 was used for making mix. Fine aggregate obtained from river bed having less amount of clay i.e. less than $3 \%$ was used and it is of size retained on 1.19 micron IS sieve. Coarse aggregate used passes from $20 \mathrm{~mm}$ and retained over $11.4 \mathrm{~mm}$ sieve. Concrete mix of grade M20 was used for making of cube specimen. To know the mix proportion, mix design was carried out as per code IS:10262-1982 (Reaffirmed -2004) (BIS:10262- 1982, Reaffirmed-2004)[7] and mix proportion of 1:1.698:2.94 with watercement ratio of 0.5 was obtained. The strength of concrete mix was checked by casting and testing of cubes. Cubes of size $150 \times 150 \times 150 \mathrm{~mm}$ were casted, cured and tested after 7 and 28 days.

\section{Experimental Investigation of CFPT}

Moulds of size $150 \times 150 \times 150 \mathrm{~mm}$ were taken and all interior faces were coated with oil. PVC tube of $100 \mathrm{~mm}$ internal diameter, $2 \mathrm{~mm}$ thick and $120 \mathrm{~mm}$ height was placed inside the mould at centre as per the literature by Gopi and Sujitha (2017).[2] Concrete mix of M20 grade was poured inside the tube and mould with hand compaction by a steel rod having point ends to poke concrete. Total 6 cube specimens were casted, striped after 24 hours and placed in curing tank for curing till required days. Cube specimens were tested under Universal Testing Machine after 7 days and 28 days for compressive strength. Load is applied on opposite side of specimen as casted till the specimen breaks or load starts decreasing and load-displacement data was taken from UTM. Rate of loading for test was $140 \mathrm{~kg} / \mathrm{cm}^{2} / \mathrm{min}$ as per IS $516: 1959$ [8] and it should be increased gradually till specimen fails.

\begin{tabular}{|c|c|c|c|}
\hline Specimen & Ultimate Load $(\mathrm{kN})$ & Compressive Strength $(\mathrm{MPa})$ & Displacement at Ultimate Load (mm) \\
\hline $\mathrm{C} 1$ & 339.72 & 15.09 & 5.00 \\
\hline $\mathrm{C} 2$ & 321.78 & 14.30 & 4.20 \\
\hline C3 & 355.08 & 15.78 & 4.70 \\
\hline Average & 338.86 & 15.06 & 4.63 \\
\hline
\end{tabular}

Table 1: 7 Days' Test Results

Table 1 shows test results after 7 days where average ultimate load taken by cube specimen was $338.86 \mathrm{kN}$ and average displacement was $4.633 \mathrm{~mm}$. Table 2 shows test results after 28 days where average ultimate load taken by cube specimen was $414.7 \mathrm{kN}$ and average displacement was $5.233 \mathrm{~mm}$ with compressive strength of 18.429 $\mathrm{MPa}$.

\begin{tabular}{|c|c|c|c|}
\hline Specimen & Ultimate Load $(\mathrm{kN})$ & Compressive Strength $(\mathrm{MPa})$ & Displacement at Ultimate Load $(\mathrm{mm})$ \\
\hline $\mathrm{C} 1$ & 387.30 & 17.21 & 5.30 \\
\hline C2 & 406.80 & 18.08 & 4.50 \\
\hline C3 & 449.80 & 19.99 & 5.90 \\
\hline Average & 414.70 & 18.43 & 5.23 \\
\hline
\end{tabular}

Table 2: 28 Days' Test Results 
Figure 1 illustrates stress-strain curve for all cube specimen plotted from load-displacement data obtained from UTM on single graph along with average of all curves. It can be seen in Fig. 1 that average modulus of elasticity of concrete cube was obtained as, $\mathrm{Ec}=533.175 \mathrm{MPa}$. These above results of cube i.e. Modulus of Elasticity of concrete cube and average displacement were used in modelling in code ANSYS.

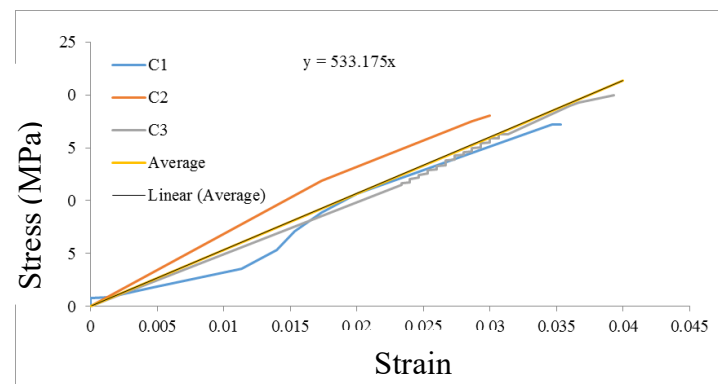

Fig. 1: Stress-Strain Curve for Cube Specimen

\section{Validation of Results and Comparison}

A three-dimensional model of cube size $150 \times 150 \times 150 \mathrm{~mm}$ was made and PVC tube of $100 \mathrm{~mm}$ diameter, 120 $\mathrm{mm}$ height and $2 \mathrm{~mm}$ thick was made at centre in ANSYS. Fig. 2 shows the model of PVC tube placed inside cube. Properties of materials like modulus of elasticities of concrete $\mathrm{Ec}=533.175 \mathrm{MPa}$ and modulus of elasticities of PVC pile Ep $=702.9 \mathrm{MPa}$ were computed experimentally and were incorporated in ANSYS model. Displacement support was applied at bottom of cube and displacement of $5.233 \mathrm{~mm}$ (obtained from experimental work) was applied at top surface. Force reaction and normal stress was obtained after solving in ANSYS. Fig. 3 shows the variation of normal stresses obtained from ANSYS software.

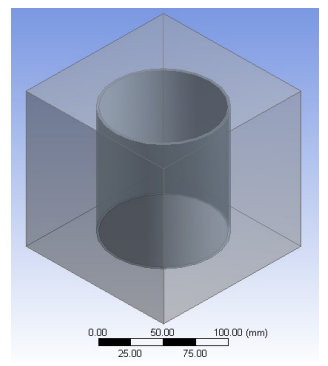

Fig. 2: 3D Model of CPVT

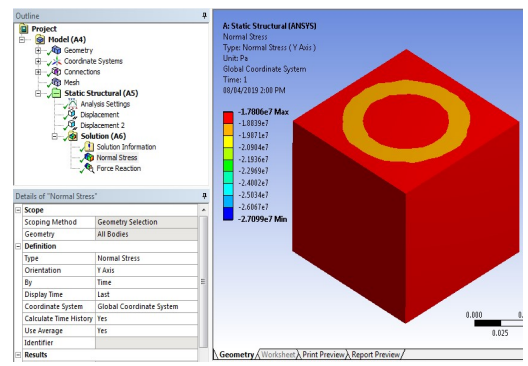

Fig. 3: Normal Stresses

Results from ANSYS are compared with the experimental results and percentage deviation was calculated. Table 3 shows the results from ANSYS and experimental results along with their percentage deviation.

\begin{tabular}{|l|c|c|c|}
\hline \multicolumn{1}{|c|}{ Quantities } & Experimental Results & ANSYS Results & Percentage Deviation \\
\hline Ultimate Load $(\mathrm{kN})$ & 414.70 & 422.21 & $1.81 \%$ \\
\hline Compressive stress $(\mathrm{MPa})$ & 18.43 & 18.32 & $0.57 \%$ \\
\hline
\end{tabular}

Table 3: Comparison of Results

From table 3 , it is clear that percentage deviation in ultimate load taken by cube is $1.81 \%$ whereas in compressive strength the deviation is $0.577 \%$. As percentage deviation is very less so further work can be done on model to satisfy the objectives.

\section{Parametric Study}

Tube used for experimental work was having diameter of $100 \mathrm{~mm}$ and thickness of $2 \mathrm{~mm}$. To keep D/t i.e. diameter to thickness ratio of tube constant, the tube dimensions of $75 \mathrm{~mm}$ internal diameter with $1.5 \mathrm{~mm}$ thickness, $100 \mathrm{~mm}$ internal diameter with $2 \mathrm{~mm}$ thickness and $125 \mathrm{~mm}$ internal diameter with $2.5 \mathrm{~mm}$ thickness were used for modelling.

\section{Behaviour of Model by Changing Diameter and Thickness of Tube}

Making different combinations of diameter and thickness, nine combinations were made with $75 \mathrm{~mm} 100 \mathrm{~mm}$, 125 internal diameters with $1.5 \mathrm{~mm}, 2.0 \mathrm{~mm}, 2.5 \mathrm{~mm}$ thickness, etc. For every combination, computer simulation using ANSYS was carried out for similar loading and boundary conditions used for validation of model. The simulation results are obtained in from of normal stress in concrete, normal stress in tube, hoop stress in tube, etc. were obtained and shown in table 4. 


\begin{tabular}{|c|c|c|c|c|c|}
\hline $\begin{array}{c}\text { Inner } \\
\text { Dia. } \\
(\mathrm{mm})\end{array}$ & $\begin{array}{c}\text { Thickness } \\
(\mathrm{mm})\end{array}$ & $\begin{array}{c}\text { Normal Stress } \\
\text { in conc. }(\mathrm{MPa})\end{array}$ & $\begin{array}{c}\text { Normal Stress in } \\
\text { tube (MPa) }\end{array}$ & $\begin{array}{c}\text { Hoop Stress in } \\
\text { tube (MPa) }\end{array}$ & $\begin{array}{c}\text { Force } \\
\text { Reaction (kN) }\end{array}$ \\
\hline 75 & 1.5 & 18.62 & 26.85 & 6.32 & 420.60 \\
\hline 75 & 2.0 & 18.60 & 27.13 & 6.42 & 421.31 \\
\hline 75 & 2.5 & 18.53 & 26.62 & 6.23 & 422.02 \\
\hline 100 & 1.5 & 18.58 & 26.75 & 6.28 & 421.28 \\
\hline 100 & 2.0 & 18.47 & 26.68 & 6.15 & 422.21 \\
\hline 100 & 2.5 & 18.43 & 26.56 & 6.10 & 423.14 \\
\hline 125 & 1.5 & 18.55 & 26.62 & 6.13 & 421.95 \\
\hline 125 & 2.0 & 18.44 & 26.50 & 6.08 & 423.10 \\
\hline 125 & 2.5 & 18.39 & 26.49 & 6.04 & 424.25 \\
\hline
\end{tabular}

Table 4: Results from ANSYS for Varying Diameter and Thickness of Tube

It can be observed from Table 4 that hoop stress in tube and normal stress in concrete decrease with the increase in diameter for constant thickness. Similar reduction in hoop stress in tube and normal stress in concrete was observed when thickness of the tube increase for constant diameter.

\section{Behaviour of Model by Changing Number of Tubes}

Computer simulation was also extended to understand the behavior of CFPT with more number of PVC tubes. Two sets of models were prepared wherein comparison was carried out between single CFPT with four CFPT. In the first set, two models were made wherein, first model has single tube of $75 \mathrm{~mm}$ diameter with $1.5 \mathrm{~mm}$ thickness and second model has four tubes with $37.5 \mathrm{~mm}$ diameter with $1.5 \mathrm{~mm}$ thickness. In the second set, first model has single tube with $100 \mathrm{~mm}$ diameter with $2 \mathrm{~mm}$ thickness whereas second model has four tubes with $50 \mathrm{~mm}$ diameter with $2 \mathrm{~mm}$ thickness. These dimensions were chosen so that the area of confined concrete by single and 4 PVC tubes remains same. The simulation using ANSYS was carried out for similar loading and boundary conditions used for validation of model. Table 5 shows the results of computer simulation in from of stresses and forces obtained from ANSYS. It is observed that for same area of confined concrete, force reaction increases and normal stress in concrete decreases with increase in number of CFPT.

\begin{tabular}{|c|c|c|c|c|c|c|c|}
\hline $\begin{array}{c}\text { Thickness } \\
(\mathrm{mm})\end{array}$ & $\begin{array}{c}\text { Inner Dia. } \\
(\mathrm{mm})\end{array}$ & $\begin{array}{c}\text { Area of } \\
\text { Confined } \\
\text { Concrete } \\
\left(\mathrm{mm}^{2}\right) \\
\end{array}$ & $\begin{array}{l}\mathrm{C} / \mathrm{s} \text { Area of } \\
\text { PVC }\left(\mathrm{mm}^{2}\right)\end{array}$ & $\begin{array}{l}\text { Normal } \\
\text { Stress in } \\
\text { conc. } \\
(\mathrm{MPa})\end{array}$ & $\begin{array}{c}\text { Normal } \\
\text { Stress in } \\
\text { tube } \\
(\mathrm{MPa}) \\
\end{array}$ & $\begin{array}{c}\text { Hoop } \\
\text { Stress in } \\
\text { tube } \\
(\mathrm{MPa})\end{array}$ & $\begin{array}{c}\text { Force } \\
\text { Reaction } \\
(\mathrm{kN})\end{array}$ \\
\hline \multirow{2}{*}{1.5} & 75 & \multirow{2}{*}{4417.86} & 360.49 & 18.62 & 26.85 & 6.33 & 420.60 \\
\hline & 4 of 37.5 & & 735.13 & 18.55 & 26.68 & 5.72 & 422.74 \\
\hline \multirow{2}{*}{2} & 100 & \multirow{2}{*}{7853.98} & 640.88 & 18.47 & 26.68 & 6.15 & 422.21 \\
\hline & 4 of 50 & & 1306.90 & 18.37 & 26.59 & 6.10 & 425.97 \\
\hline
\end{tabular}

Table 5: Results from ANSYS for Varying Number of Tubes

\section{Behavior of Model by Changing L/D Ratio}

To understand the effect of change in $\mathrm{L} / \mathrm{D}$ ratios, tube dimensions of $100 \mathrm{~mm}$ diameter and $2 \mathrm{~mm}$ thick was used for modelling. The length of model was increased so that various L/D ratios can be obtained. After successful computer simulation using ANSYS for similar loading and boundary conditions used for validation of model, the results are obtained and presented in Table 6.

\begin{tabular}{|c|c|c|c|c|c|c|}
\hline $\begin{array}{c}\text { Inner } \\
\text { Dia. } \\
(\mathrm{mm})\end{array}$ & $\begin{array}{c}\text { Thickness } \\
(\mathrm{mm})\end{array}$ & $\begin{array}{c}\text { L/D } \\
\text { Ratio }\end{array}$ & $\begin{array}{c}\text { Normal Stress } \\
\text { in } \\
\text { conc. }(\mathrm{MPa})\end{array}$ & $\begin{array}{c}\text { Normal Stress } \\
\text { in } \\
\text { tube (MPa) }\end{array}$ & $\begin{array}{c}\text { Hoop Stress in } \\
\text { tube (MPa) }\end{array}$ & $\begin{array}{c}\text { Force } \\
\text { Reaction }(\mathrm{kN})\end{array}$ \\
\hline \multirow{4}{*}{100} & & 1 & 18.47 & 26.68 & 6.15 & 422.21 \\
\cline { 3 - 7 } & \multirow{3}{*}{2} & 2 & 9.32 & 13.32 & 2.97 & 211.34 \\
\cline { 3 - 7 } & & 3 & 6.21 & 8.94 & 1.87 & 140.95 \\
\cline { 3 - 7 } & & 4 & 4.66 & 6.76 & 1.38 & 105.73 \\
\cline { 3 - 7 } & & 5 & 3.71 & 5.39 & 1.05 & 84.59 \\
\hline
\end{tabular}

Table 6: Results from ANSYS for varying $L / D$ ratio

It is observed from Table 6 that for same average displacement, there is a decrease in normal stress in concrete, hoop stress in tube and force reaction with increase in $\mathrm{L} / \mathrm{D}$ ratio. This is due to the decrease in strain in specimen. 


\section{Conclusion}

In this paper, the experimental and computational study on CFPT placed in columns is presented. Experimental study was carried out by casting and testing of CFPT placed concrete cubes whereas the computational study was carried out on a FE model using ANSYS code. The following conclusion was drawn from the above study.

i. Experimental investigation shows that the behavior of CFPT placed in column is ductile due to PVC placed inside.

ii. Experimental investigation also shows that cube specimen fails due to crushing at corner when placed under UTM for compression testing.

iii. In computational investigation, it is observed that compressive strength of CFPT placed in column has increased with increase in area of confined concrete inside PVC tube by increasing the diameter of PVC tube. So, it can be concluded that strength of CFPT placed in column is directly proportional to the diameter of PVC tube and area of infill concrete.

iv. Computational study also shows that there is an improvement in strength of CFPT placed in column with increase in the thickness of PVC tube. Improvement in strength is also observed when more number of tubes is used in place of single tube.

v. Computational study indicates that the normal stress in concrete and reaction forces reduces with the increase in $\mathrm{L} / \mathrm{D}$ ratio.

\section{References}

1. Gobinath G, Selvi K (2014) An Experimental Study on Behaviour Of RC Column with PVC Cover. International Journal of Engineering Research \& Technology 3:1112-1117.

2. Gopi N, Sujitha B (2017) Behaviour Of Concrete Filled PVC Tubes (CFPT) Placed in Columns. International Conference on Emerging trends in Engineering, Science and Sustainable Technology, Organized by Erode Sengunthar Engineering College, Perundurai, Erode. https://www.internationaljournalssrg.org.

3. Gupta PK (2013) Confinement of Concrete Columns with Unplasticized Poly-Vinyl Chloride Tubes. International Journal of Advanced Structural Engineering 5:19.

4. Gupta PK, Sarda SM, Kumar MS (2006) Experimental and computational study of concrete filled steel tubular columns under axial loads. Journal of Constructional Steel Research 63:182-193.

5. Gupta PK, Verma VK (2014) Study of concrete-filled unplasticized poly-vinyl chloride tubes in marine environment. Journal of Engineering for the Maritime Environment 230:229-240.

6. Idan FK (2017) Finite Element Analysis of Concrete-filled Aluminum tube columns. International Journal of Applied Engineering Research 12:3054-3062.

7. IS 10262 (1982) Concrete Mix Design-Code of Practice, Bureau of Indian Standard, New Delhi.

8. IS 516 (1959) Method of Tests for Strength of Concrete, Bureau of Indian Standard, New Delhi.

9. Usha CM, Eramma H (2014) Experimental Study on Concrete Filled, Unplasticized Poly Vinyl

Chloride (UPVC) Tubes. International Journal of Advanced Technology in Engineering and Science 2:331-338.

10. Wang W, Sheikh MN et al (2016) Experimental Study on FRP Tube Reinforced Concrete Columns under Different Loading Conditions. American Society of Civil Engineers 1-11. 